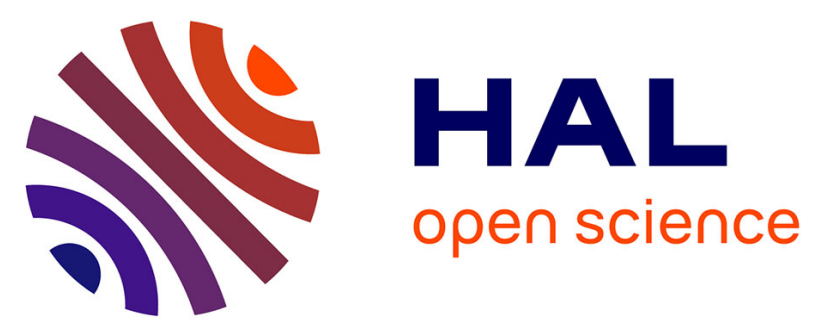

\title{
Fate of coagulant species and conformational effects during the aggregation of a model of a humic substance with Al13 polycations
}

V. Kazpard, B.S. Lartiges, C. Frochot, J.B. D'espinose de La Caillerie, M.L. L Viriot, Jean-Michel Portal, T. Görner, J.L. Bersillon

\section{To cite this version:}

V. Kazpard, B.S. Lartiges, C. Frochot, J.B. D'espinose de La Caillerie, M.L. L Viriot, et al.. Fate of coagulant species and conformational effects during the aggregation of a model of a humic substance with Al13 polycations. Water Research, 2006, 40 (10), pp.1965-1974. 10.1016/j.watres.2006.03.014 . hal-02265622

\section{HAL Id: hal-02265622 \\ https://hal.science/hal-02265622}

Submitted on 10 Aug 2019

HAL is a multi-disciplinary open access archive for the deposit and dissemination of scientific research documents, whether they are published or not. The documents may come from teaching and research institutions in France or abroad, or from public or private research centers.
L'archive ouverte pluridisciplinaire HAL, est destinée au dépôt et à la diffusion de documents scientifiques de niveau recherche, publiés ou non, émanant des établissements d'enseignement et de recherche français ou étrangers, des laboratoires publics ou privés. 


\section{FATE OF COAGULANT SPECIES AND CONFORMATIONAL EFFECTS DURING THE AGGREGATION OF A MODEL OF A HUMIC SUBSTANCE WITH AL 13 POLYCATIONS}

V. Kazpard ${ }^{1}$, B.S. Lartiges ${ }^{1}{ }^{*}$, C. Frochot ${ }^{2}$, J.B. d'Espinose de la Caillerie ${ }^{3}$, M.L. Viriot $^{2}$, J.M. Portal ${ }^{4}$, T. Görner ${ }^{1}$, J.L. Bersillon ${ }^{1}$

1 University of Nancy - LEM-ENSG/INPL-CNRS, Pôle de l'Eau 15 Avenue du

Charmois - BP 4054501 Vandoeuvre Cedex, France

2 Département de Chimie Physique des Réactions (CDPR-GRAPP), UMR 7630 ENSICCNRS-INPL, 1 rue Grandville, BP 451, 54500 Nancy, France

${ }^{3}$ ESPCI - Laboratoire de Physique Quantique, 10 Rue Vauquelin, 75231 Paris Cedex, France

${ }^{4}$ CRPG-CNRS, 15 Rue Notre Dame des Pauvres, BP 5 54501 Vandoeuvre Cedex, France

corresponding author: bruno.lartiges@get.omp.eu 


\begin{abstract}
A model of a humic substance (MHS) obtained from autooxidation of catechol and glycine, was aggregated at $\mathrm{pH} 6$ and 8 with $\mathrm{Al}_{13}$ polycations. The fate of $\mathrm{Al}_{13}$ coagulant species upon association with MHS functional groups was studied using solid state ${ }^{27} \mathrm{Al}$ MAS NMR and CP-MAS ${ }^{13} \mathrm{C}$ NMR. Electrophoretic measurements and steady-state fluorescence spectroscopy with pyrene as a fluoroprobe, were combined to investigate structural re-organization of humic material with aluminum concentration. MAS ${ }^{27} \mathrm{Al}$ NMR revealed that the coagulant species are $\mathrm{Al}_{13}$ polycations or oligomers of $\mathrm{Al}_{13}$ units at both pHs. CP MAS ${ }^{13} \mathrm{C}$ spectra indicated that, at low $\mathrm{Al}$ concentration, hydrolyzed aluminum species bind selectively to carboxylic groups at $\mathrm{pH} 6$ and to phenolic moieties at $\mathrm{pH}$ 8. At higher coagulant concentrations, the remaining functional groups also interact with hydrolyzed $\mathrm{Al}$ to yield similar CP MAS ${ }^{13} \mathrm{C}$ spectra in the optimum concentration range. Negative values of electrophoretic mobility were obtained at optimum coagulant concentrations even though an overall charge balance was achieved between MHS anionic charge and $\mathrm{Al}_{13}$ cationic charge at $\mathrm{pH}$. The polarity-sensitive fluorescence of pyrene revealed that the interaction of $\mathrm{Al}_{13}$ coagulant species with MHS functional groups induces the formation of intramolecular hydrophobic microenvironments. Such structural changes were reversed upon further addition of $\mathrm{Al}_{13}$ polycations.
\end{abstract}

Key words: Coagulation, humic substances, $\mathrm{Al}_{13}$ polycation. 


\section{INTRODUCTION}

Optimizing natural organic matter (NOM) removal by coagulation is a crucial challenge in drinking water treatment. Indeed, the organic material remaining within the clarified water is involved in most problems encountered in the treatment process such as reduced adsorption capacity in activated carbon beds, formation of carcinogenic chlorinated organic compounds during disinfection, taste and odour of the finished water, and biological regrowth in the distribution networks (Owen et al., 1995). Several mechanisms have been proposed to explain the interaction of NOM with hydrolyzed coagulant species. Charge neutralization is thought to occur at low $\mathrm{pH}$ as suggested by stoichiometric relationships between coagulant demand and dissolved organic matter concentration, or restabilization upon overdosing (Narkis and Rehbun, 1977), whereas under conditions favoring metal hydroxide precipitation, physical entrapment and/or adsorption of organic matter onto the freshly formed precipitate are assumed to play a major role in NOM removal (Bose and Reckhow, 1998).

However, none of the above destabilization mechanisms account for the low removal efficiency which does not exceed 60 percent in most cases (Jacangelo et al. 1995). NOM is in fact a very complex mixture of organic components derived from soils or produced within surface waters and sediments by biological and chemical processes. Recent research has shown that larger molecular weight molecules are more effectively removed than smaller ones, and that the hydrophobic fraction of NOM is more easily destabilized by coagulation than hydrophilic compounds (Collins et al., 1986; Bose and Reckow, 1998). Selectivity also depends on coagulant nature, as polysaccharides are more amenable to removal with aluminum polychlorosulfate, whereas polyhydroxyaromatics are preferentially eliminated by ferric chloride (VilgéRitter et al., 1999). Another difficulty in identifying NOM destabilization mechanisms concerns the speciation of hydrolyzable metal salts used as coagulants. Even though, the aqueous chemistry of aluminum and iron based coagulants is now much better described, the formation of hydrolyzed metal species can be altered in the presence of 
NOM. Thus, the hydrolysis of ferric chloride is hindered to the trimer stage at both $\mathrm{pH} 5$ and 7 (Vilgé-Ritter et al., 1999), while hydrolyzed aluminum species have been shown to be depolymerized by natural organic ligands (Masion et al., 2000).

The aim of this work was to investigate the destabilization mechanism of a model of a humic substance (MHS) with $\mathrm{Al}_{13}$ polycations as a function of both $\mathrm{pH}$ and aluminum concentration. $\mathrm{Al}_{13}$ polycations are formed during hydrolysis of most commercial polyaluminum chloride coagulants (Wang et Hsu, 1994; Lartiges et al., 1997), whereas humic substances generally represent more than $50 \%$ of the dissolved NOM in lake and river waters (Zumstein and Buffle, 1989). MHS was obtained from auto-oxidation of catechol and glycine (Jung et al., 2005). As the structure and basic chemical properties of natural humic substances are still a matter of debate, the definition and representativity of a synthetic model may always be discussed. Nevertheless, extensive characterization of MHS and comparison with humic extracts from Moselle river water, revealed that such a synthesis yields organic molecules with elemental composition, titration features, spectral and fluorescence characteristics, similar to that of naturally occuring humic substances (Jung et al., 2005). Furthermore, an Electron Energy Loss Spectroscopy (EELS) investigation of the coagulation of MHS and natural counterparts with a ferric salt, showed the same coagulation behavior for both organic colloids (Jung et al., in press), thus suggesting that MHS may represent a standard humic material suitable to compare the destabilization mechanism associated with various coagulants.

In this study, Magic-angle spinning (MAS) ${ }^{27} \mathrm{Al}$ NMR was used to investigate the fate of aluminum coagulant species during MHS aggregation, while crosspolarization magic-angle spinning (CP-MAS) ${ }^{13} \mathrm{C}$ NMR allowed to examine the nature of association reached between the aluminum polycations and the functional groups of MHS. Electrophoretic mobility provided valuable information about the overall charge of the MHS-coagulant association. Possible reconformation of the humic material may occur upon interaction with coagulant species. Fluorescence spectroscopy with pyrene 
as a polarity-sensitive probe was then used to investigate the conformational changes of MHS in presence of $\mathrm{Al}_{13}$ polycations.

\section{MATERIALS AND METHODS}

Preparation of a model of a humic substance. MHS was synthesized by autooxidation from an aqueous equimolar mixture of catechol and glycine $(0.03 \mathrm{~mol} / \mathrm{L}$ in a 2 L flask) (Jung et al., 2005). The reaction was conducted in the dark under constant stirring for 5 days. The temperature was maintained at $20^{\circ} \mathrm{C}$ and the $\mathrm{pH}$ was fixed at 7.9 with a phosphate buffer. The oxidative polymerization resulted in a dark-brown product which was purified by dialysis $(6-8 \mathrm{~kg} / \mathrm{mol}$ Spectra Por 6) against distilled water to yield a humic-like substance in a sodium form. MHS was then freeze-dried and stocked as a dry powder.

Humic substances are traditionally categorized into humins, humic acids, and fulvic acids, on the basis of their water solubility. At $\mathrm{pH}<2$, about $85 \%$ of our synthetic product is insoluble which defines MHS as a humic acid. Elemental analysis of MHS (Carlo Erba 1108 autoanalyser) indicated contents of $45.6 \%$ in $\mathrm{C}, 3.6 \%$ in $\mathrm{H}, 2.5 \%$ in N, and $48.3 \%$ in $\mathrm{O}$. Such values are consistent with the mean composition of freshwater humic acids indicated in the literature (Krasner et al., 1996). The total titrable charge of MHS (3.7 meq/g between $\mathrm{pH} 3.5-10.5)$ and the contents in carboxylic and weakly acidic groups (respectively 3.1 and $0.6 \mathrm{meq} / \mathrm{g}$ ), are also in good agreement with the values reported for river water humic substances (Christensen et al., 1998). However, even though humic molecules are known to aggregate, the use of a $6-8 \mathrm{~kg} / \mathrm{mol}$ dialysis cut-off is expected to yield a material with a larger molecular weight than the 1-3 $\mathrm{kg} / \mathrm{mol}$ generally reported for aquagenic humic material (Beckett et al., 1987). Such a synthesis is also expected to yield organic polymeric colloids (Swift, 1999), rather than supramolecular assemblies (Piccolo, 2001). Nevertheless, fluorescence monitoring of 
MHS synthesis suggested that the humic-like fluorescent compound was formed from the association of oligomeric quinonic species (Jung et al., 2005).

Preparation of $\mathbf{A l}_{13}$ stock solution. The $\mathrm{Al}_{13}$ coagulant solution was prepared by dissolving analytical grade $\mathrm{AlCl}_{3} \cdot 6 \mathrm{H}_{2} \mathrm{O}$ (Aldrich) in deionized water (MilliQ 18.5 M $\Omega$ ), and then by adding dropwise $\mathrm{NaOH} 0.45 \mathrm{M}$ solution $(0.4 \mathrm{~mL} / \mathrm{min})$ under vigorous stirring to an hydrolysis molar ratio $\mathrm{OH} / \mathrm{Al}$ of 2.25 and a total $\mathrm{Al}$ concentration of 0.1 M. Previous ${ }^{27} \mathrm{Al}$ NMR investigations revealed that such synthesis conditions essentially yield $\mathrm{AlO}_{4} \mathrm{Al}_{12}(\mathrm{OH})_{24}\left(\mathrm{H}_{2} \mathrm{O}\right)_{12}$ isolated polycations in the partially hydrolyzed solution (Bottero et al., 1980). The $\mathrm{Al}_{13}$ polycation possesses a Keggin structure, which consists of a central tetrahedrally coordinated aluminum $\left(\mathrm{Al}^{\mathrm{IV}}\right)$ surrounded by 12 edge-linked octahedral aluminum sites $\left(\mathrm{Al}^{\mathrm{VI}}\right)$.

Preparation of suspensions and aggregation procedure. Suspensions were obtained by dissolving $30 \mathrm{mg}$ of MHS in $1 \mathrm{~L}$ of deionised water, thus yielding a Total Organic Carbon (TOC) concentration of $12 \mathrm{mg} / \mathrm{L}$. Such concentration is consistent with average TOC values usually reported for river waters (Meybeck, 1982). $\mathrm{NaHCO}_{3}\left(410^{-3} \mathrm{~mol} / \mathrm{L}\right.$ ) was also added to the synthetic water to provide $\mathrm{pH}$ and ionic strength buffers similar to that of Seine river water. Prior to coagulant injection, the $\mathrm{pH}$ of suspensions was adjusted to $\mathrm{pH} 6$ or 8 with dropwise addition of $0.5 \mathrm{M} \mathrm{HCl}$.

Aggregation of MHS with $\mathrm{Al}_{13}$ polycations was performed in a standard $1 \mathrm{~L}$ glass beaker (90 mm diameter, $150 \mathrm{~mm}$ high) fitted with four Plexiglas baffles. Stirring was carried out with a $15 \mathrm{~mm} \times 54 \mathrm{~mm}$ blade positioned at one-third the height of the reactor from the bottom. A stirring rate of $100 \mathrm{rpm}$, which corresponds to a spatially averaged velocity gradient $\mathrm{G}$ of $135 \mathrm{~s}^{-1}$, was used for all the experiments. The required amount of $\mathrm{Al}_{13}$ solution was added under agitation with a syringe at a point just below the free surface of the suspension. The time of injection was about $3 \mathrm{~s}$. pH was not readjusted after coagulant addition as the drop in suspension $\mathrm{pH}$ resulting from further hydrolysis of the coagulant never exceeded $0.4 \mathrm{pH}$ unit for the largest aluminum 
concentration used at $\mathrm{pH}$ 8. Stirring was continued at $100 \mathrm{rpm}$ for 20 minutes, and at the end of mixing, the aggregated suspension was allowed to settle for $24 \mathrm{~h}$ in graduated Imhoff cones. The supernatant was then analyzed for its turbidity (Hach turbidimeter), TOC (Dorhman 190), and residual aluminum concentration (ICP-AES Jobin-Yvon 70 type B model with external calibration). The sediment was collected and dialysed against deionized water for 5 days to remove added ions. It was then freeze-dried for NMR studies. Preliminary ${ }^{27} \mathrm{Al}$ MAS NMR experiments indicated that the MHS-Al aggregates do not evolve significantly during settling and dialysis.

Electrophoretic mobility. The electrophoretic mobility of unsettled aggregates was determined with a Zetaphoremeter III (Sephy, France) equipped with a CCD camera. Prior to the measurements, the supernatant of the settled suspensions was centrifuged at $2500 \mathrm{rpm}$ for 10 minutes in a lab-centrifuge (Eppendorf 5804) to increase the concentration in particles. The centrifugate was then re-suspended in $50 \mathrm{ml}$ of original supernatant before being pumped into the electrophoretic cell. This procedure may induce a slight compaction of the floc structure. However, such a rearrangement occurs at a much larger scale than that associated with the diffuse double layer. The velocity of particles located at the stationary layer was directly computed from a video analysis obtained at fixed time intervals under an $80 \mathrm{mV}$ applied voltage.

Magic-angle spinning nuclear magnetic resonance (MAS-NMR). The MAS-NMR spectra were recorded on a Bruker ASX 500 instrument in $4 \mathrm{~mm}$ zirconia rotors with polyimide endcaps. One-pulse ${ }^{27} \mathrm{Al}(\mathrm{I}=5 / 2)$ spectra were recorded at $130.32 \mathrm{MHz}$, spinning at $14 \mathrm{kHz}$ with recycle delays of $1 \mathrm{~s}$ and 400 transients. Small pulse widths $(<$ $\pi / 2(2 \mathrm{I}+1)$ were used with duration of $0.5 \mathrm{~s}$ to obtain quantitative responses. $\left\{{ }^{1} \mathrm{H}-{ }^{13} \mathrm{C}\right\}$ cross-polarization CP/MAS-NMR spectra were obtained at $125.77 \mathrm{MHz}$, spinning at 10 $\mathrm{kHz}$, with $<\pi / 2{ }^{1} \mathrm{H}$ pulse of $8 \mathrm{~s}$, contact times of $1 \mathrm{~ms}$, recycle delays of $5 \mathrm{~s}$ and around 14000 transients. Line broadening procedure $(100 \mathrm{~Hz})$ was applied before Fourier transform, and the chemical shifts were quoted relative to $\mathrm{Al}\left(\mathrm{H}_{2} \mathrm{O}\right)_{6}{ }^{3+}$ and TMS for ${ }^{27} \mathrm{Al}$ 
and ${ }^{13} \mathrm{C}$ respectively. Resonance intensities were obtained by integration for ${ }^{27} \mathrm{Al}$ and by decomposition into lorentzian components for ${ }^{13} \mathrm{C}$.

Fluorescence measurements. One liter solutions containing $30 \mathrm{mg}$ MHS and $336 \mathrm{mg}$ $\mathrm{NaHCO}_{3}$ in deionised water were first prepared and adjusted to either $\mathrm{pH} 6$ or 8 with dropwise addition of $0.5 \mathrm{M}$ HCL. $5 \mathrm{~mL}$ aliquots of MHS solution were then placed in glassware beakers and mixed with $5 \mu \mathrm{L}$ of pyrene stock solution $\left(10^{-3} \mathrm{M}\right.$ pyrene (Aldrich 99+\%) in ethanol (Carlo Erba 99.5\%), thus yielding a pyrene concentration of the order of $1 \mu \mathrm{M}$ for all fluorescence measurements. The volumetric content of ethanol introduced in the samples did not exceed $0.1 \%$ and does not influence the solubility of pyrene in samples. $\mathrm{Al}_{13}$ coagulant was then injected, and the aggregated MHS-pyrene suspension was allowed to equilibrate for one hour. Prior to fluorescence measurements, the samples were re-homogeneized by over-hand shaking.

Steady-state fluorescence measurements were performed on a Fluorolog-2 spectrofluorometer (SPEX, Edison), using $0.5 \mathrm{~mm}$ slits for the excitation and emission monochromators. All spectra were recorded at room temperature. In order to compare the fluorescence intensities of all fluorescence spectra and to avoid equipment baseline time drift, the fluorescence was normalised with a $0.16 \mathrm{mg} / \mathrm{L}$ fluorescein solution buffered at $\mathrm{pH} 10$, using an excitation wavelength of $488 \mathrm{~nm}$ with emission recorded from 450 to $550 \mathrm{~nm}$. Pyrene excitation wavelength was set at $332 \mathrm{~nm}$ and the emission was collected between 350 and $450 \mathrm{~nm}$. Even though MHS absorbance remained significant at the excitation wavelength, the background emission of the synthetic material was negligible and represented less than $2 \%$ of the total measured pyrene probe fluorescence. The polarity sensitive ratio $I_{1} / I_{3}$ was calculated from the emission intensities at $372\left(\mathrm{I}_{1}\right)$ and $383 \mathrm{~nm}\left(\mathrm{I}_{3}\right)$.

Preliminary blank experiments indicated negligible variations in MHS background emission in presence of various $\mathrm{Al}_{13}$ concentrations. It was also checked that pyrene fluorescence spectra were not affected by the addition of increasing concentrations of coagulants, and that the amount of $\mathrm{Cl}^{-}$anion contained in the 
aluminum coagulant solution had no quenching effect in the concentration range used. Furthermore, the emission spectra failed to reveal any excimer peak.

\section{RESULTS AND DISCUSSION}

Aggregation results. The effect of varying concentrations of $\mathrm{Al}_{13}$ coagulant solution on MHS aggregation at both $\mathrm{pH} 6$ and 8, is illustrated in figure 1. Three curves are shown, settled water turbidity, sediment volume, and residual aluminum concentration, each as a function of aluminum dosage. Figure 1a reveals that, at low aluminum concentration and for both $\mathrm{pHs,}$, the supernatant turbidity increases steadily with coagulant dosage to reach a maximum, and then decreases steeply upon further increase in aluminum concentration. The point where the extrapolated steep portion of the turbidity curve intersects the $\mathrm{x}$-axis was chosen as the optimum coagulant concentration (OCC), and is indicated with an arrow on the graph. For our synthetic water, OCC values of about $2.410^{-4}$ and $4.210^{-4} \mathrm{~mol} / \mathrm{L}$ were found at $\mathrm{pH} 6$ and 8 , respectively. Excellent organic removal is then provided as more than $95 \%$ TOC is eliminated at both optimum coagulant dosages. At higher aluminum concentrations, the residual turbidity remains very low at $\mathrm{pH} 8$, whereas it increases strongly above a $4.710^{-4} \mathrm{~mol} / \mathrm{L}$ coagulant concentration at $\mathrm{pH} 6$ to reach a constant turbidity of about 12 NTU.

The drop in supernatant turbidity observed just before the OCC at pHs 6 and 8 corresponds to the formation of settleable aggregates as evidenced by a rapid build-up in sediment volume in this concentration range (figure 1b). Above the OCC, the sediment volume increases slightly at $\mathrm{pH} 8$ to reach a plateau value, while it diminishes sharply at $\mathrm{pH} 6$ as MHS is restabilized. The evolution of residual aluminum concentration follows the same general pattern as the supernatant turbidity curve (figure 1c): at low coagulant dosages, the residual aluminum concentration increases proportionally to the coagulant concentration, and then drops at the OCC to a similar $3.10^{-5} \mathrm{~mol} / \mathrm{L}$ value for both $\mathrm{pHs}$. Such a behavior clearly reveals a strong association between MHS and hydrolyzed aluminum species. At $\mathrm{pH}$ 6, upon restabilization of the 
suspension, the residual aluminum concentration resumes its linear increase with coagulant dosage.

The difference in OCC concentration observed between $\mathrm{pH} 6$ and 8 is the result of both an increased deprotonation of MHS functional groups and a decreased charge of coagulant species at $\mathrm{pH}$ 8. In the aluminum concentration range of OCCs, potentiometric titrations showed that the charge of the $\mathrm{Al}_{13}$ polycation is about $6+$ at $\mathrm{pH}$ 6, and $1+$ at $\mathrm{pH} 8$ (Furrer et al., 1992). It can then be calculated that at $\mathrm{pH} 6$, the amount of charge brought by the coagulant species at OCC $(\sim 3.3 \mathrm{meq} / \mathrm{g})$ is equivalent to the carboxylic acidity of the humic-like polymer $(3.1 \mathrm{meq} / \mathrm{g})$. On the other hand, at $\mathrm{pH} 8$, the optimal coagulant demand represents a charge of $1.1 \mathrm{meq} / \mathrm{g}$, i.e. about 3.3 times less than required to neutralize all the anionic groups available. This, at first, seems to substantiate previous literature indicating that different mechanisms are responsible for humic substances removal according to $\mathrm{pH}$ (e.g. Dempsey et al., 1984).

Fate of coagulant species. Figure 2 shows the ${ }^{27} \mathrm{Al}$ MAS NMR spectra obtained for MHS coagulated at both $\mathrm{pH} 6$ and 8 with different aluminum concentrations. All spectra exhibit two prominent resonances at about 3 and $63 \mathrm{ppm}$, and two weaker less resolved peaks at about 33 and $64.5 \mathrm{ppm}$.

The 63 ppm signal can be unambiguously assigned to the central tetrahedrally coordinated aluminum in the $\mathrm{Al}_{13}$ polycation (Bottero et al., 1980). The strong slightly asymetric $3 \mathrm{ppm}$ signal falls within the six coordinate chemical shift region of aluminum and is similar to values reported for the dimer $\mathrm{Al}_{2}(\mathrm{OH})_{2}{ }^{4+}$ (Masion et al., 2000), and for monomeric and oligomeric species of aluminum complexed with low molecular weight organic acids (Masion et al., 1994). However, closer examination of the spectra reveals that the maximum of this resonance shifts gradually from 2 to $7 \mathrm{ppm}$ with increasing aluminum concentration and $\mathrm{pH}$ (figure 3a). Previous NMR investigations of fresh $\mathrm{Al}_{13}$ precipitates have attributed such a shift to octahedral aluminum in polymeric species of $\mathrm{Al}_{13}$ units of increasing degree of polymerization (Bradley et al., 1993; Lartiges et al., 1997). Recent EXAFS and NMR studies of Ga 13 
aggregates have shown that the association of Keggin polycations occurs through double corner sharing coordinated water molecules (Lartiges et al., in preparation). In comparison with isolated $\mathrm{Al}_{13}$ polycations, an increase in symmetry and deshielding is then expected for the aluminum octahedra upon the formation of $\mathrm{Al}_{13}$ oligomers. The decrease of Full Width at Half Height (FWHH) of the octahedral resonance with aluminum concentration is consistent with such a view (figure $3 b$ ).

The peaks at 64.5 and 33 ppm have been previously identified in solutions of $\mathrm{Al}_{13}$ tridecamers aged at high temperature (Fu et al., 1991; Allouche et al., 2000), and in powders obtained from $\mathrm{AlCl}_{3} /$ urea hydrolyzed sols (Wood et al., 1990). The $33 \mathrm{ppm}$ signal, indicative of a five-coordinate Al (Wood et al., 1990), is not stable in solution and is necessarily generated during the freeze-drying of sediments. Assignment of the $64.5 \mathrm{ppm}$ resonance is controversial as it has been attributed (i) to the tetrahedral site of a 12 aluminum polycation $\left(\mathrm{Al}{ }^{\mathrm{VI}} / \mathrm{Al} \mathrm{IV}^{\mathrm{IV}}=11\right)$ arising from the loss of one octahedral $\mathrm{Al}$ from an $\mathrm{Al}_{13}$ unit (Fu et al., 1991), (ii) to an $\mathrm{Al}_{13}$ Keggin structure capped with 1 to 3 $\mathrm{AlO}_{6}$ octahedra (Allouche et al., 2000). Nevertheless, both polycations have been described as intermediate species formed during the oligomerization of $\mathrm{Al}_{13}$ units, which is in accordance with the increase of the $64.5 \mathrm{ppm}$ peak area with $\mathrm{Al}$ concentration (figure 2).

A rough estimate of the $\mathrm{Al}{ }^{\mathrm{IV}}$ to Alt contributions reveals that the $\mathrm{Al} \mathrm{IV}^{\mathrm{IV}}$ Alt ratio is greater than 8 in the aluminum concentration range investigated by solid state ${ }^{27} \mathrm{Al}$ $\mathrm{NMR}$ (figure $3 \mathrm{c}$ ). Therefore, $\mathrm{Al}_{13}$ polymers and aluminum polycations with a $\mathrm{Al}{ }^{\mathrm{VI}} / \mathrm{Al}{ }^{\mathrm{IV}}$ $<12$, are the dominating species within dialyzed coagulated MHS. Previous reports indicated that low molecular weight organic acids hinder aluminum hydrolysis (Masion et al., 2000) and depolymerize preformed $\mathrm{Al}_{13}$ polycations (Molis et al., 1996; Amirbahman et al., 2000). Our results suggest that, in the OCC range and in the timescale of the experiment, the $\mathrm{Al}_{13}$ coagulant species seem to be stable in presence of MHS, which is consistent with previous evidence of $\mathrm{Al}_{13}$ polycations found in organic soil horizons (Hunter and Ross, 1991). Nevertheless, some depolymerization of $\mathrm{Al}_{13}$ polymers may occur as the $\mathrm{Al} / \mathrm{V} / \mathrm{Alt}$ ratio is observed to decrease at lower coagulant 
dosages. Attempts to determine the speciation of aluminum with liquid state ${ }^{27} \mathrm{Al}$ NMR at low aluminum concentration were unsuccessful, thus indicating that the aluminum species are strongly associated with the humic material.

Interestingly, Figure 3 reveals some kind of continuity as a function of aluminum concentration between values obtained at $\mathrm{pH} 6$ and 8 for percent of tetrahedral aluminum, FWHH of octahedrally coordinated species, and octahedral aluminum chemical shift. This suggests that the size and degree of polymerization of $\mathrm{Al}_{13}$ units increase regularly with coagulant concentration irrespective of $\mathrm{pH}$. In other terms, ${ }^{27} \mathrm{Al}$ NMR does not reveal any contrasting behavior in the formation of coagulant species between $\mathrm{pH} 6$ and 8, or low and high aluminum concentrations. Thus, the formation of a voluminous mass of aluminum hydroxyde precipitate usually reported in the sweep-flocculation domain (e.g. Edwards and Amirtharajah, 1985) is not detected.

Interaction between coagulant species and MHS functional groups. The CP-MAS ${ }^{13} \mathrm{C}$ NMR spectra of MHS coagulated with various aluminum concentrations at $\mathrm{pH} 6$ and 8 are shown in figure 4. All spectra display major signals at about 176, 145, and 117 ppm which are easily assigned to carboxylic carbon, phenolic ring carbon (aromatic-oxygen bound), and aromatic ring carbon, respectively (Inbar et al., 1989). In addition, the original non coagulated MHS exhibits a small peak at about $85 \mathrm{ppm}$, which is characteristic of aliphatic carbon singly bonded to oxygen or nitrogen (Stuermer and Payne, 1976).

The main characteristic of the CP-MAS technique is that the magnetization is transferred to ${ }^{13} \mathrm{C}$ from neighboring protons ${ }^{1} \mathrm{H}$ through dipolar coupling which is strongly distance dependent: in other terms, ${ }^{13} \mathrm{C}$ that are close to protons generally cross-polarize more efficiently than ${ }^{13} \mathrm{C}$ that are some distance away from a proton. Applied to MHS-Al aggregates, ${ }^{13} \mathrm{C}$ CP-MAS NMR may be used to probe the presence of highly hydrated coagulant species in the vicinity of a given functional group. Thus, at $\mathrm{pH} 6$, the relative abundance of the peak at $176 \mathrm{ppm}$ increases with aluminum 
concentration to become predominant for $[\mathrm{Al}] \geq 2.610^{-4} \mathrm{~mol} / \mathrm{L}$. Such a result is then in agreement with the picture of positive coagulant species anchored on negatively charged carboxylic groups. Likewise, the 117 ppm resonance, poorly resolved at low coagulant concentration, is enhanced at higher aluminum dosage. Previous studies have shown that MHS carboxylic groups originate in part from the cleavage of catechol aromatic rings during oxydative polymerization (Hänninen et al., 1987). Therefore, it is not surprising that the evolutions of carboxyl and aromatic carbon resonances can be related. Interestingly, the carboxylic to aromatic $\mathrm{C}$ ratio increases linearly with aluminum concentration up to the COC as illustrated in figure 5a. Finally, just before restabilization of aggregates, the $117 \mathrm{ppm}$ signal increases strongly. This suggests that phenolic groups are available for association with $\mathrm{Al}_{13}$ polycations in presence of excess coagulant.

At $\mathrm{pH} 8$, the ${ }^{13} \mathrm{C}$ CP-MAS NMR spectra obtained above the OCC closely resemble the spectra at $\mathrm{pH} 6$ with similar proportions of carboxyl, phenolic ring, and aromatic ring carbons in the optimal concentration range. However, at $\mathrm{pH} 8$, the intensities of carboxyl, phenolic, and aromatic peaks are almost equivalent at low coagulant dosages (figure 4), with the aromatic peak significantly dominating at $[\mathrm{Al}]=$ $4.10^{-4} \mathrm{~mol} / \mathrm{L}$. This suggests that the ionized functional groups of MHS do not interact with $\mathrm{Al}_{13}$ polycations in the same order according to $\mathrm{pH}$. Thus, the enhanced aromatic carbon signal at $\mathrm{pH} 8$, indicates that the aluminum hydrolyzed species preferentially associate with phenolic moieties in the low coagulant concentration range, and then with carboxylic functional groups at higher aluminum dosages. The carboxylic to aromatic carbon ratios obtained at $\mathrm{pH} 8$ further illustrate such a view (figure $5 \mathrm{~b}$ ).

Electrophoretic mobility of Al-MHS aggregates. The electrophoretic mobilities of MHS coagulated at $\mathrm{pH} 6$ and 8 with various concentrations of $\mathrm{Al}_{13}$ polycations, are shown in figure 6. Up to the OCC, the aggregates present a constant negative mobility at both $\mathrm{pH} 6$ and 8 although the humic-like substance coagulated well in this concentration range. Therefore, in contrast to oxide or clay colloidal particles 
aggregated with metal hydrolyzable coagulants (e.g. James et al., 1977), the mobility curve of MHS aggregates provides no indication of the optimal coagulation zone. This implies that the destabilisation mechanism operating at $\mathrm{pH} 6$ can not correspond to a simple charge neutralization of $\mathrm{MHS}$ with $\mathrm{Al}_{13}$ polycations. Above $\mathrm{OCC}$, the electrophoretic mobilities reduce to less negative values until charge reversal of aggregates. Comparison with the Jar test results indicates that at $\mathrm{pH} 6$, the restabilization of aggregates begins with nearly neutral aggregates, whereas at $\mathrm{pH} 8$, the lower positive electrophoretic mobilities obtained in presence of excess coagulant seem insufficient to trigger MHS redispersion. This effect can be ascribed to a difference in binding strength between the coagulant species formed at $\mathrm{pH} 6$ and 8 . Indeed, $\mathrm{Al}_{13}$ polycations, charged $6+$ at $\mathrm{pH} 6$ should be more effective in changing the conformation of humic chains, than the lesser charged coagulant species formed at $\mathrm{pH}$ 8. Such a reorganization of MHS chains around positive coagulant species would then yield the negative electrophoretic mobilities observed in the optimal removal range at both $\mathrm{pH} 6$ and 8.

Pyrene fluorescence in MHS coagulated suspensions. Figure 7 illustrates the aluminum concentration dependence of the $\mathrm{I}_{1} / \mathrm{I}_{3}$ fluorescence intensity ratio at $\mathrm{pHs} 6$ and 8. In order to facilitate the discussion, electrophoretic mobility results are also plotted on the same graph. The intensity ratio of the first and third vibronic peaks in the pyrene fluorescence spectrum is known to provide a good solvent polarity sensor at the local scale (Kalyanasundaram and Thomas, 1977). In pure water, $\mathrm{I}_{1} / \mathrm{I}_{3}$ is about 1.9 , while it is much lower in an apolar medium (e.g. $\mathrm{I}_{1} / \mathrm{I}_{3} \sim 0.6$ in hexane). The recorded value of $I_{1} / I_{3}$ is then an average of that reported for pyrene associated with MHS and pyrene in the bulk aqueous phase.

In the original MHS suspension, $\mathrm{I}_{1} / \mathrm{I}_{3}$ is equal to 1.8 which indicates an average solvent environment of pyrene slightly less polar than water. Upon addition of the aluminum coagulant, $\mathrm{I}_{1} / \mathrm{I}_{3}$ decreases at both $\mathrm{pH} 6$ and 8 to reach a minimum for $[\mathrm{Al}]=$ $1.410^{-4} \mathrm{~mol} / \mathrm{l}$. This suggests that the pyrene probe has been solubilized within a more 
hydrophobic environment. Such a behavior can be explained by (i) an increased partition of pyrene into newly created hydrophobic domains, and/or (ii) a reorganization of humic chains in the vicinity of previously sorbed pyrene molecules. However, as the fluoroprobe is expected to be largely associated with MHS prior to the addition of $\mathrm{Al}_{13}$ polycations (Chin et al., 1997; Kopinke et al., 2001), the second hypothesis is favored. The minimum values measured for $\mathrm{I}_{1} / \mathrm{I}_{3}$, about 1.75 at both $\mathrm{pH} 6$ and 8 , are in close agreement with $I_{1} / I_{3}$ intensity ratios found for Latahco silt loam humic acid in the presence of $\mathrm{MgCl}_{2}$ (Engebretson and von Wandruszka, 1997).

Further increase in coagulant dosage reverts the evolution of $\mathrm{I}_{1} / \mathrm{I}_{3}$, and the initial environmental polarity around pyrene molecules is restored for aluminum concentrations of $4.410^{-4}$ and $710^{-4} \mathrm{~mol} / \mathrm{l}$ at $\mathrm{pHs} 6$ and 8 , respectively. This peculiar phenomenon can be compared with a demicellization process at the macromolecule scale. As increasing amounts of $\mathrm{Al}_{13}$ polycations are added to the MHS suspension, the coagulant species are expected to compete for the negatively charged moieties of humic chains. Therefore, instead of being attached onto functional groups of more than one chain thus determining intramolecular bridging links, the positive coagulant species become associated with individual carboxylic and phenolic groups, which eventually results in electrostatic repulsion between humic chains. The gradual reduction in electrophoretic mobility of MHS-Al aggregates to zero in this range of concentration, corroborates such a view.

\section{CONCLUSION}

In the $\mathrm{pH}$ range relevant to drinking water treatment, the removal of humic substances is generally described by at least two destabilization mechanisms according to $\mathrm{pH}$ and coagulant concentration. Contrary to this widely accepted view, our results suggest a similar $\mathrm{MHS} / \mathrm{Al}_{13}$ aggregation at both pHs 6 and 8 . A comparable conclusion was reached by Vilgé-Ritter et al. (1999b) in her combined EXAFS and SAXS study of NOM destabilization with ferric chloride at $\mathrm{pH} 5.5$ and 7.5. 
Until a consensus can be reached regarding the structure and conformation of humic substances, any investigation carried out with a synthetic anologous of humic material will remain arguable. However, our study suggests that a reorganization of anionic humic chains occurs upon association with the positively charged coagulant species. Such a conclusion is consistent with humic acids viewed as soft and permeable structures (Duval et al., 2005). It is also in accordance with previous EELS results, obtained with both MHS and natural humic substances, suggesting that the optimal coagulant concentration depends on the interplay between the rate of collisions of humic colloids/coagulant species, and the rate of organic material reconformation (Jung et al., 2005). In that case, for a given collision rate, larger molecular weight material with lower reconformation rate, should be removed prior to lower molecular weight organic colloids.

\section{ACKNOWLEDGMENTS}

This work was supported from funds provided by Suez-Lyonnaise des Eaux, France. This support is gratefully acknowledged. V.K. and B.S.L. thank CRPG-CNRS, Nancy France for ICP-AES analysis, Bernadette Gérard for help with the synthesis of MHS at CPB-CNRS, Nancy, France and Ka Yan Leung for help with the electrophoretic measurements. 


\section{REFERENCES}

Allouche, L., Gérardin, C., Loiseau, T., Férey, G., Taulelle, F. (2000) $\mathrm{Al}_{30}$ : A giant aluminum polycation. Angew. Chem. Int. Ed. 39, 511-514

Amirbahman, A., Gfeller, M., Furrer, G. (2000) Kinetics and mechanism of ligand promoted decomposition of the Keggin $\mathrm{Al}_{13}$ polymer. Geochim. Cosmochim. Acta. 64, 911-919

Beckett, R., Zhang, J., Giddings, J.C. (1987) Determination of molecular weight distributions of fulvic and humic acids using flow field-flow fractionation. Environ. Sci. Technol. 21(3), 289295

Bose, P., Reckhow, D. A. (1998) Adsorption of natural organic matter on preformed aluminum hydroxide flocs. J. Environmental Engineering 803-811

Bottero, J. Y., Cases, J. M., Fiessinger, F., Poirier, J. E. (1980) Studies of hydrolyzed aluminum chloride solutions. 1. Nature of aluminum species and composition of aqueous solutions. J. Phys. Chem. 84, 2933-2939

Bradley, S. M., Kydd, R. A., Russell, F. H. (1993) The structure of Al gels formed through the base hydrolysis of $\mathrm{Al}^{3+}$ aqueous solutions. J. Colloid Interface Sci. 159, 405-412.

Chin, Y.-P., Aiken, G.R., Danielsen, K.M. (1997) Binding of pyrene to aquatic and commercial humic substances: the role of molecular weight and aromaticity. Environ. Sci. Technol. 31(6), 1630-1635

Collins, M. R., Amy, G. L., Steelink, C. (1986) Molecular weight distribution, carboxilic acidity, and humic substances content of aquatic organic matter : implications for removal during water treatment. Environ. Sci. Technol. 20, 1028-1032

Christensen, J. B., Tipping, E., Kinniburgh, D. G.; Gron, C.; Christensen, T. H. (1998) Proton binding by gruwndwater fulvic acids of different age, origins, and structure modeled with the model V and nica-donnan model. Environ. Sci. Technol. 32, 3346-3355

Dempsey, B. A., Ganho, R. M., O’Melia, C. R. (1984) The coagulation of humic substances by means of aluminum salts. Jour. AWWA 76, 141-150

Duval, J.F.L., Wilkinson, K.J., van Leeuwen, H.P., Buffle, J. (2005) Humic substances are soft and permeable: evidence from their electrophoretic mobilities. Environ. Sci. Technol. (in press)

Edwards, G. A. and Amirtharajah, A. (1985) Removing color caused by humic acids. Jour. AWWA 77, 50-57

Engebretson, R.R. and von Wandruszka, R. (1997) The effect of molecular size on humic acid associations. Org. Geochem. 26(11-12), 759-767.

Fu, G., Nazar, L. F., Bain, A. D. (1991) Aging processes of alumina sol-gels : characterization of new aluminum polyoxycations by ${ }^{27} \mathrm{~A} 1 \mathrm{NMR}$ spectroscopy. Chem. Mater. 3, 602-610.

Furrer, G.; Ludwig, C., Schindler, P. W. (1992) On the chemistry of the keggin Al13 polymer. I. Acid-base properties. J. Colloid Interface Sci. 149, 56-67 
Hänninen, K. I., Klöcking, R., Helbig, B. (1987) Synthesis and characterization of humic acid-like polymers. The science of the total environment 62, 201-210

Hunter, D. and Ross, D. S. (1991) Evidence of phytotoxic hydroxy-aluminum polymer in organic soil horizons. Science 251, 1056-1058

Inbar, Y., Chen, Y., Hadar, Y. (1989) Solid state carbon 13 nuclear magnetic resonance and infrared spectroscopy of composed organic matter. Soil. Sci. Soc. Am. J. 53, 1695-1701.

Jacangelo, J. G., DeMarco, J., Owen, D. M., Randtke, S. J. (1995) Selected processes for removing NOM. Jour. AWWA 87, 64-77

James, R.O., Wiese, G.R., Healy, T.W. (1977) Charge reversal coagulation of colloidal dispersions by hydrolysable metal ions. J. Colloid Interface Sci. 59(2), 381-385.

Jung, A.-V., Frochot, C., Parant, S., Lartiges, B.S., Selve, C., Viriot, M.-L., Bersillon, J.-L. (2005) Synthesis of amino-phenolic humic-like substances and comparison with natural aquatic humic acids: A multi-analytical techniques approach. Organic Geochemistry 36(9), 1252-1271.

Jung, A.-V., Chanudet, V., Ghanbaja, J., Lartiges, B.S., Bersillon, J.-L. (in press) Coagulation of humic substances and dissolved organic matter with a ferric salt: an Electron Energy Loss Spectroscopy investigation. Water Research

Kalyanasundaram, K., and Thomas, J.K.J. (1977) Environmental effects on vibronic band intensities in pyrene monomer fluorescence and their application in studies of micellar systems. J.Am. Chem. Soc. 99(7), 2039-2044.

Kopinke, F.D., Georgi, A., Mackenzie, K. (2001) Sorption of pyrene to dissolved humic substances and related model polymers. 1. Structure-property correlation. Environ. Sci. Technol. 35, 25362542.

Krasner, S. W.; Croué, J. P.; Buffle, J.; Perdue, M. (1996) Three approaches for characterizing NOM. Jour. AWWA 88, 66-79

Lartiges, B. S., Bottero, J. Y., Derrendinger, L. S., Humbert, B., Tekely, P., Suty, H. (1997) Flocculation of colloidal silica with hydrolyzed aluminum: $\mathrm{An}{ }^{27} \mathrm{Al}$ solid state NMR investigation. Langmuir 13, 147-152

Lartiges, B. S., Montargès-Pelletier, E., Barrès, O., Michot, L. J., d'Espinose de la Caillerie, J. B., Briois, V., Ponsinet, V. Aggregation of Ga13 polycations and subsequent formation of gallium oxyhydroxide $(\mathrm{GaOOH})$ : new insights from combining NMR, IR, SAXS and EXAFS. In preparation.

Masion, A., Thomas, F., Tchoubar, D., Bottero, J. Y., Tekely, P. (1994) Chemistry and structure of $\mathrm{Al}(\mathrm{OH}) /$ Organic precipitates. A small angle X-ray scattering study. 3. Depolymerization of $\mathrm{Al}_{13}$ polycation by organic ligands. Langmuir 10, 4353-4356

Masion, A., Vilgé-Ritter, A., Rose, J., Stone, W. E. E., Teppen, B. J., Rybacki, D., Bottero, J. Y. (2000) Coagulation-flocculation of natural organic matter with Al salts : speciation and structure of the aggregates. Environ. Sci. Technol. 34, 3242-3246 
Meybeck, M. (1982) Carbon, Nitrogen, and phosphorus transport by world rivers. American Journal of Science 282, 401-450

Molis, E., Thomas, F., Bottero, J. Y., Barrès, O., Masion, A. (1996) Chemical and structural transformation of aggregated Al13 polycations, promoted by salicylate ligand. Langmuir 12, 3195-3200

Narkis, N., Rebhun, M. (1977) Stoichiometry relationship between humic and fulvic acids and floculants. Jour. AWWA 69, 325-328

Owen, D. M., Amy, G. L., Chowdhury, Z. K., Paode, R., McCoy, G., Viscosil, K. (1995) NOM characterization and treatability. Jour. AWWA 87, 46-63

Piccolo, A. (2001) The supramolecular structure of humic substances. Soil Sci. 166, 810-832

Stuermer, D. H. and Payne, J. R. (1976) Investigation of seawater and terrestrial humic substances with carbon -13 and proton nuclear magnetic resonance. Geochim. Cosmochim. Acta 40, 11091114

Swift, R.S. (1999) Macromolecular properties of humic substances: fact, fiction, and opinion. Soil Sci. 164, 790-802

Vilgé-Ritter, A., Masion, A., Boulangé, T., Rybacki, D., Bottero, J. Y. (1999) Removal of natural organic matter by coagulation-flocculation : a pyrolysis-GC-MS study. Environ. Sci. Technol. 33, 3027-3032

Vigé-Ritter, A., Rose J., Masion A., Bottero J-Y., Laîné J-M. (1999b) Chemistry and structure of aggregates formed with Fe-salts and natural organic matter. Colloids Surf. 147, 297-308.

Wang, W. Z., Hsu, P. H. (1994) The nature of polynuclear OH-Al complexes in laboratory hydrolyzed and commercial hydroxyaluminum solutions. Clays and Clay minerals 42, 356-368

Wood, T. E., Siedle, A. R., Hill, J. R., Skarjune, R. P., Goodbrake, C. J. (1990) Hydrolysis of aluminium. Are all gels created equal ? Better Ceram. Chem. IV, Symp. 180, 97-116.

Zumstein, J. and Buffle, J. (1989) Circulation of pedogenic and aquagenic organic matter in an eutrophic lake. Wat. Res. 23, 229-239. 


\section{FIGURE CAPTIONS}

Figure 1. Evolution as a function of aluminum concentration of (a) residual turbidity (b) Sediment volume (c) Residual aluminum concentration in supernatant. $\mathrm{pH} 6$ filled symbols - pH 8 open symbols.

Figure 2. ${ }^{27} \mathrm{Al}$ MAS NMR spectra of freeze-dried MHS coagulated with different concentrations of aluminum at pHs 6 and 8 .

Figure 3. Evolution as a function of aluminum concentration of (a) Peak chemical shift of ${ }^{27} \mathrm{Al}$ octahedral resonances. (b) Full Width at Half Height for octahedrally coordinated species. (c) Percentage of $\mathrm{Al}^{\mathrm{IV}} / \mathrm{Alt}$ ratio. $\mathrm{pH} 6$ (filled circles) and at $\mathrm{pH} 8$ (open circles).

Figure $4 .{ }^{13} \mathrm{C}$ CP MAS NMR spectra of freeze-dried MHS coagulated with various aluminum concentrations at $\mathrm{pHs} 6$ and 8 .

Figure 5. Intensity ratio of carboxylic carbon and aromatic carbon peaks calculated from ${ }^{13} \mathrm{C}$ NMR spectra of coagulated MHS (a) $\mathrm{pH} 6$ and (b) $\mathrm{pH} 8$.

Figure 6. Evolution of the electrophoretic mobility of MHS-Al aggregates as a function of $\mathrm{Al}$ concentration at $\mathrm{pHs} 6$ and 8 .

Figure 7. Evolution of pyrene $\mathrm{I}_{1} / \mathrm{I}_{3}$ ratio intensity and electrophoretic mobility of MHSAl aggregates. (a) $\mathrm{pH}$ 6, (b) $\mathrm{pH} 8$. 

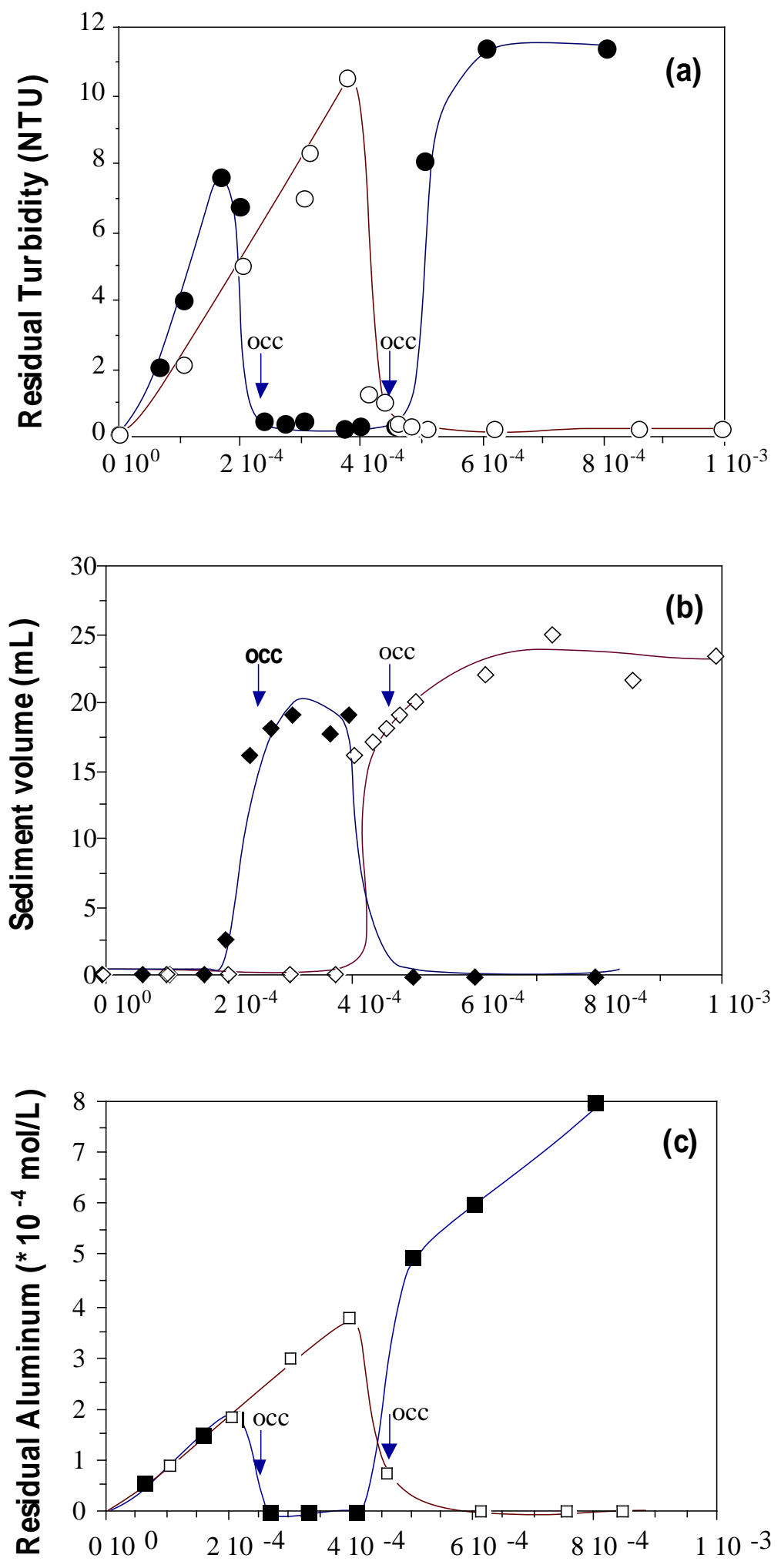

Aluminum concentration ( $\mathrm{mol} / \mathrm{L}$ )

Figure 1 

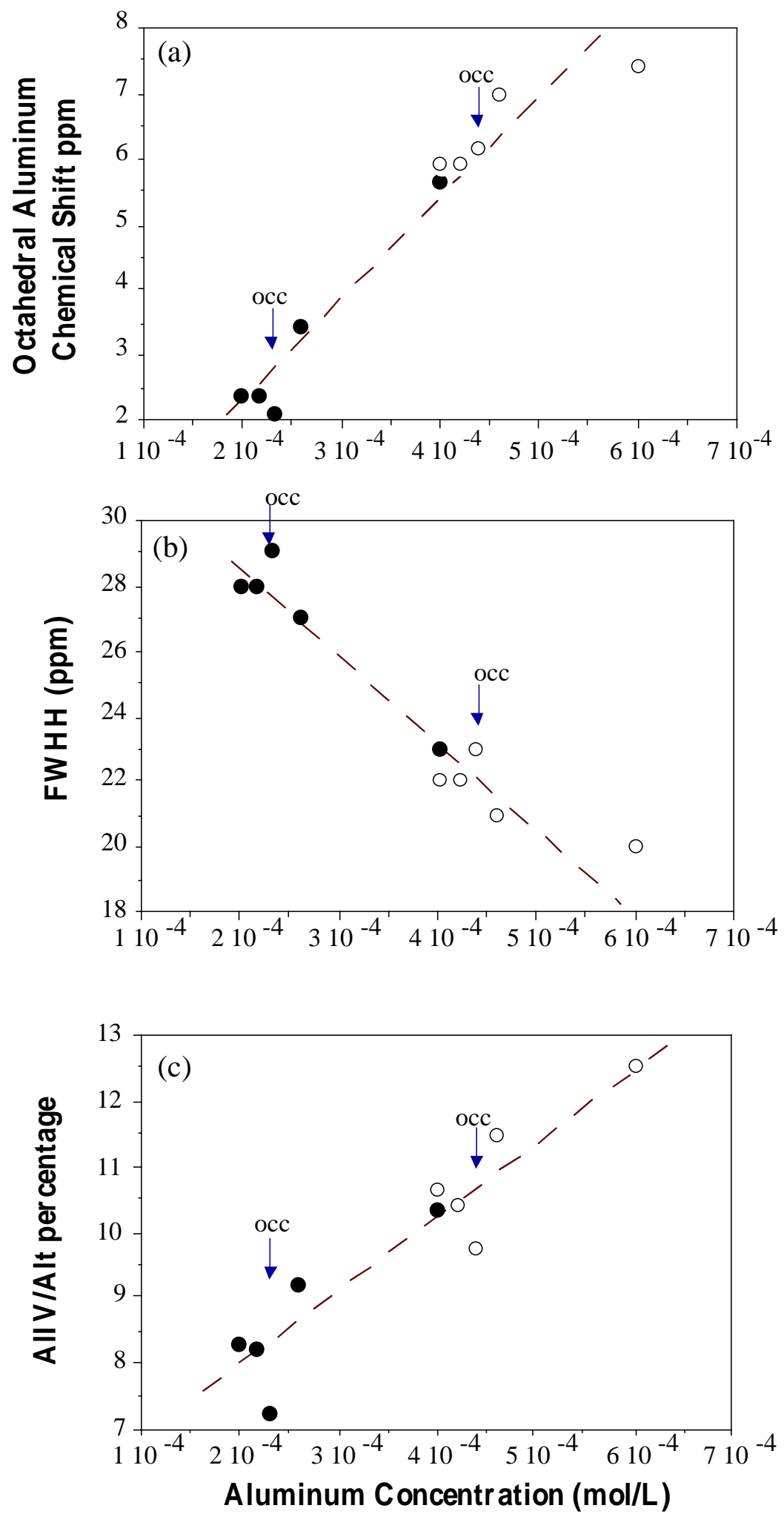

Figure 3 

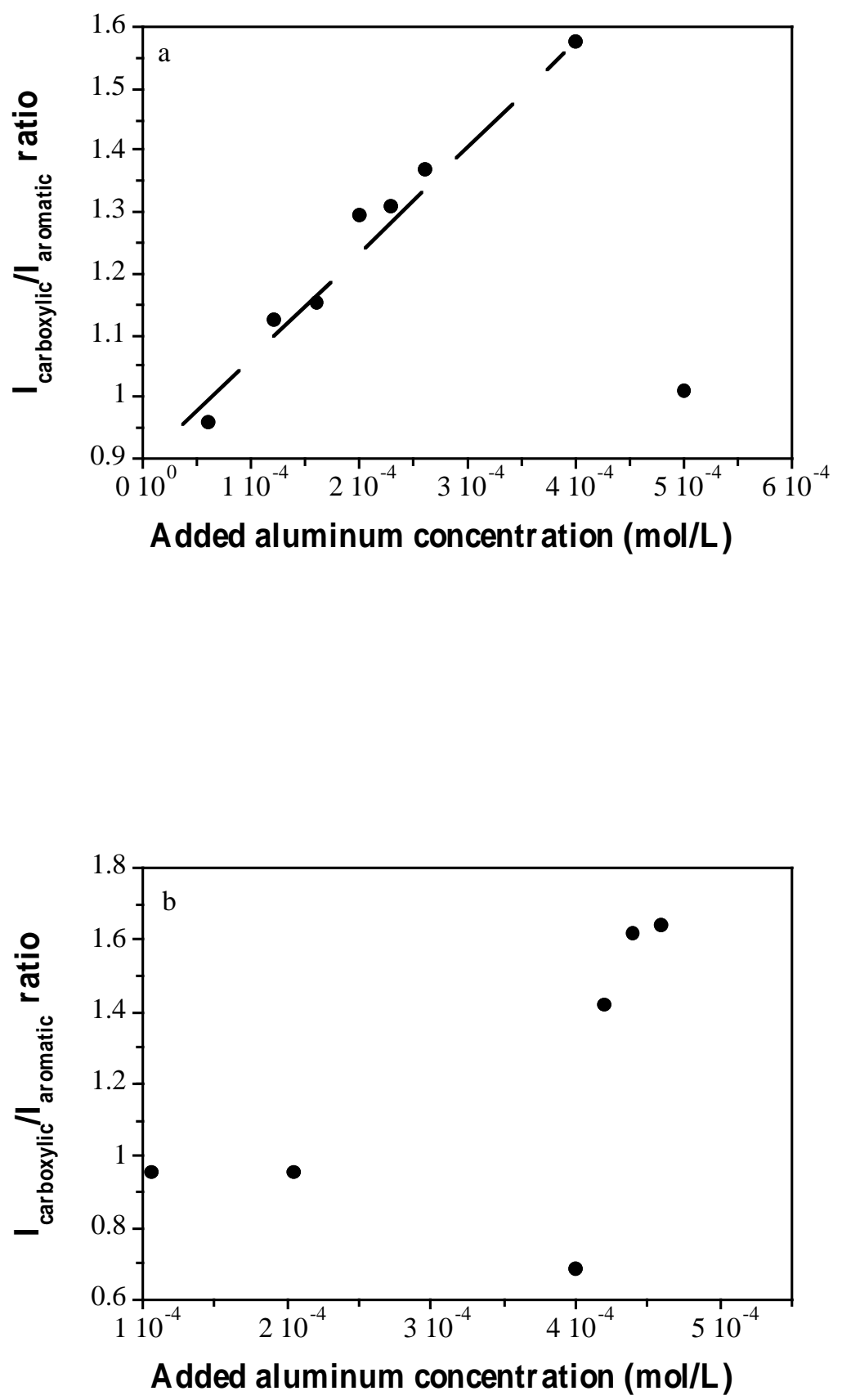

Figure 5 


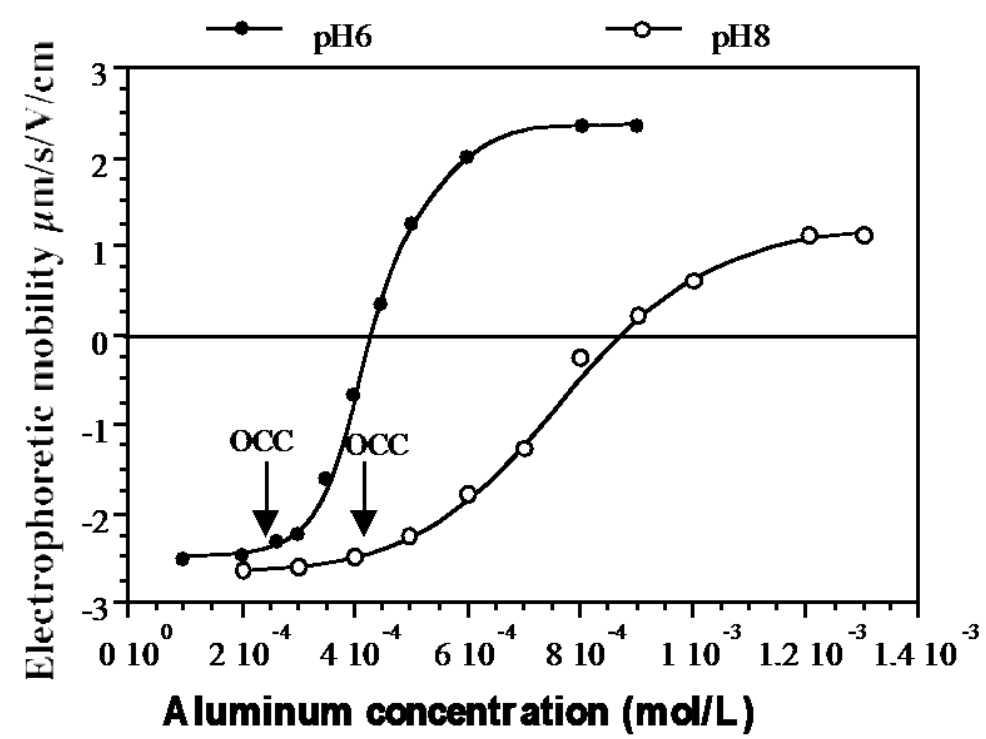

Figure 6 


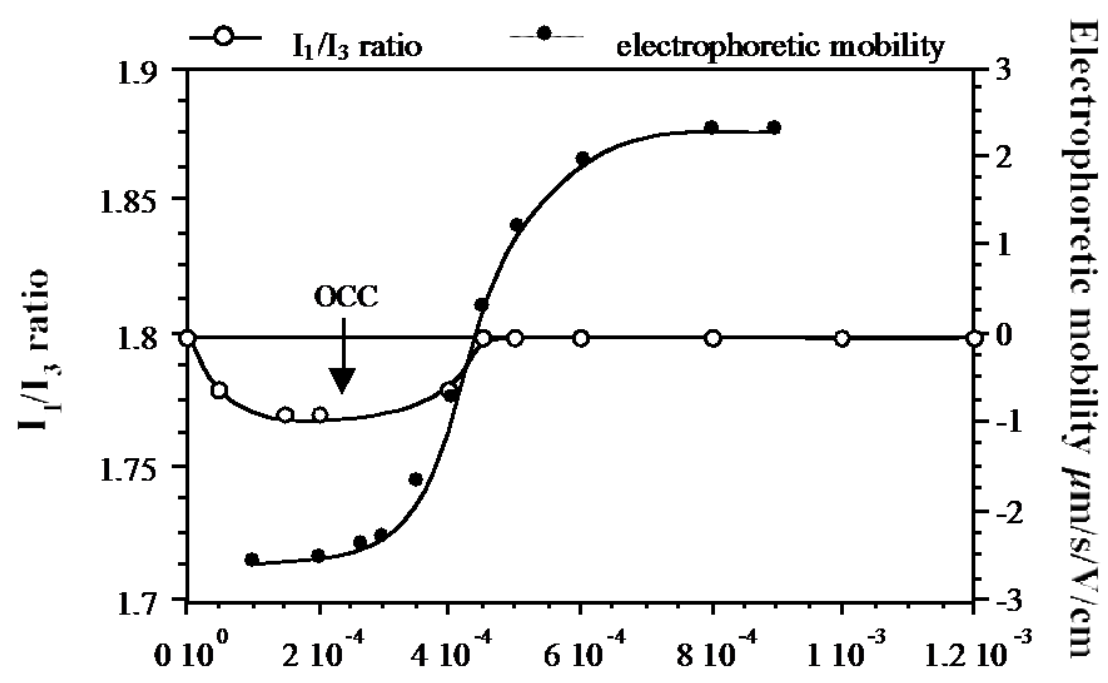

Aluminum concentration (mol/L)

Figure $7 \mathrm{a}$

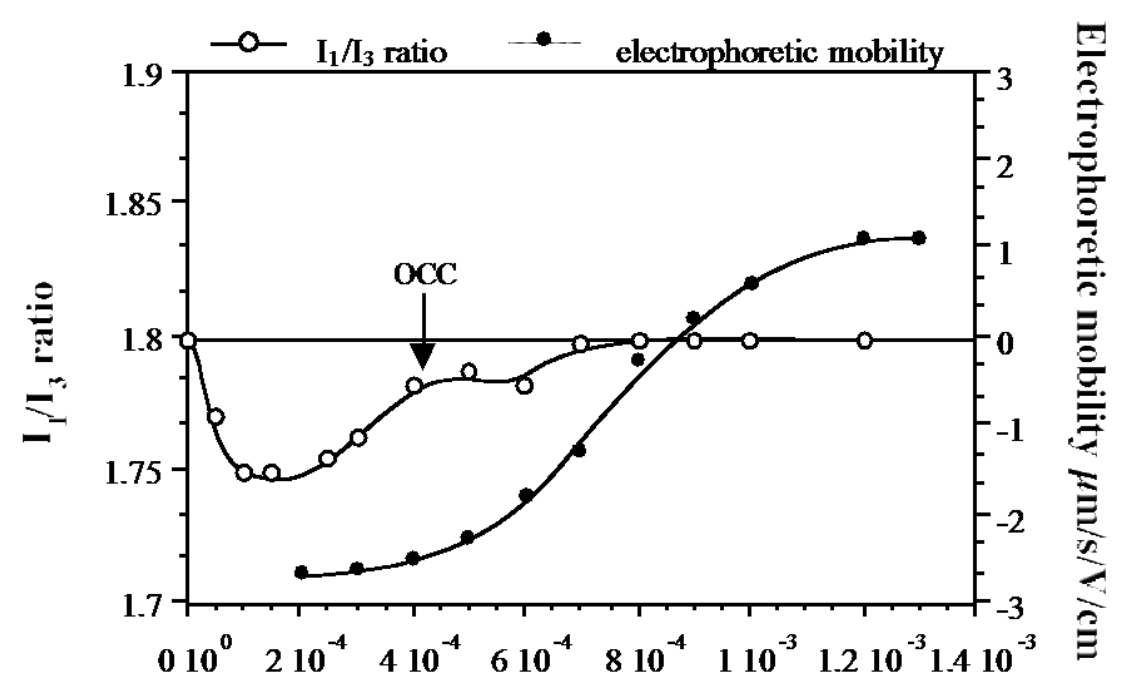

Aluminum concentration (mol/L)

Figure $7 b$ 